\title{
ASPECTOS CONTROVERTIDOS DA MORFOLOGIA: UMA ANÁLISE NORMATIVO-DESCRITIVA DA CLASSIFICAÇÃO DE VOGAIS TEMÁTICAS E DESINÊNCIAS DE GÊNNERO
}

\author{
CONTROVERSIAL MORPHOLOGY ASPECTS: AN ANALYSIS \\ REGULATORY-DESCRIPTIVE OF CLASSIFICATION THEMATIC \\ VOWEL AND INFLECTIONS GENDER
}

\author{
Jessica Maurício Schinaider ${ }^{1}$ \\ Dayane Araujo da Silva ${ }^{2}$ \\ Universidade Católica de Petrópolis
}

\section{RESUMO}

Partindo de uma das principais querelas dos estudos mórficos, isto é, a polêmica classificação das vogais temáticas e das desinências de gênero, o presente estudo propõe apresentar uma análise normativo-descritiva desse controvertido aspecto da Língua Portuguesa, dialogando com grandes estudiosos dos estudos linguísticos e teóricos normativos e descritivos, como Evanildo Bechara, Celso Cunha, José Carlos de Azeredo e Mattoso Câmara Jr.. Para tanto, ratificar-se-á a possibilidade da coexistência desses dois elementos mórficos em uma mesma palavra, por meio da desmitificação da relação de exclusividade entre as palavras terminadas em $-a$ e o gênero feminino e as palavras terminadas em -o e o gênero masculino, tão arraigadas à "gramática interna" dos falantes da Língua Portuguesa.

PALAVRAS-CHAVE: Morfologia; Vogal temática; Desinência de gênero.

\begin{abstract}
Starting from one of the main quarrels of morphic studies, the controversy classification of thematic vowels and inflections gender, this study aims to present a normative-descriptive analysis of this controversial aspect of the Portuguese language, dialogue with the great scholars of language studies and normative and descriptive theoretical, as Evanildo Bechara, Celso Cunha, José Carlos de Azeredo and Mattoso Câmara Jr.. To do so, will be ratifying the possibility of coexistence of these two morphic elements in a single word, through the demystification of exclusive relationship between words ending in -a and feminine gender, and words ending in - $\mathrm{O}$ and masculine gender, so ingrained the "inner grammar" of speakers of Portuguese.
\end{abstract}

KEYWORDS: Morphology; Thematic vowel; Inflections gender.

\footnotetext{
Pós-graduada em Língua Portuguesa pela Universidade Católica de Petrópolis. E-mail: schinaiderjessica@yahoo.com.br.

2 Pós-graduada em Língua Portuguesa pela Universidade Católica de Petrópolis. E-mail: dayanetognochi@hotmail.com.
} 


\section{INTRODUÇÃO}

O presente trabalho tem por objetivo apresentar uma análise normativo-descritiva de um controvertido aspecto da morfologia da Língua Portuguesa, isto é, a polêmica classificação das vogais temáticas nominais e das desinências de gênero; dialogando com grandes estudiosos do âmbito linguístico e teóricos normativos e descritivos, como Evanildo Bechara, Celso Cunha, Joaquim Mattoso Câmara Jr., José Carlos de Azeredo e outros.

Partindo do pressuposto de que a Gramática Normativa, tão difundida como ferramenta para o ensino do Português brasileiro nas escolas de todo o país, apresenta de forma falha, confusa e obscura os postulados referentes à Morfologia da Língua Portuguesa, eis que surge a relevância desta pesquisa, que despretensiosamente busca questionar, esclarecer e quem sabe complementar as várias explicações acerca dessa problemática questão.

Para tanto, este texto foi dividido em três partes: a primeira delas é responsável por fazer um breve panorama a respeito da importância da Morfologia para o estudo e o ensino da Língua Portuguesa; e a segunda abordará a conceituação dos elementos que constituem a controvérsia gramatical que se configura como tema desta investigação, bem como a hipótese de sua coexistência. Já a terceira e última seção, subdividida em dois tópicos, trará o diálogo entre as perspectivas normativo-descritivas dos gramáticos e dos linguistas que fazem parte do aporte teórico deste estudo.

\section{A importância da Morfologia no ensino e no estudo da Língua Portuguesa}

É fato que a fala precede a escrita, pois desde a infância todos nós já temos alguma percepção a respeito das estruturas da língua, como afirma Benites (2001 apud MOURA, 2004, p. 17):

ao entrar para a escola, uma criança é capaz de narrar, mentir, pedir,reclamar, persuadir e seduzir através da linguagem, tudo isso sem ter sido submetida à menor sistematização formal, o que leva a crer em um conhecimento implícito do indivíduo sobre sua língua muito maior do que se pode imaginar.

Para Possenti (1996), o conjunto de regras que habilita os falantes nativos da Língua Portuguesa a produzirem enunciados orais compreensíveis pode ser encarado como uma espécie de gramática internalizada. Esse conhecimento prévio é "de ordem lexical (capacidade de empregar palavras adequadas às coisas, aos processos) e de ordem sintático-semântico (distribuição das palavras nas sentenças e o efeito que tal distribuição tem para o sentido)". (MOURA, 2004, p. 20).

Partindo dessa competência prévia, o falante dará continuidade ao estudo e à prática da linguagem por meio da leitura e da escrita ao longo de sua jornada acadêmica. Assim, esses conhecimentos se tornam basilares para que os indivíduos façam uso pleno da Língua Portuguesa.

No entanto, mesmo após anos na escola, muitas pessoas ainda demonstram grande dificuldade em se expressar tanto pela linguagem oral quanto pela escrita, pois infelizmente há tempos o ensino de Língua Portuguesa é exclusivamente para fins burocráticos, ou seja, "o aluno escreve apenas para ser avaliado e aprovado" (MELO; CAVALCANTE, 2005 apud MARCUSCHI, 2007, p. 135).

Dessa forma, é imprescindível buscar estratégias de ensino e de aprendizagem capazes de consolidar uma boa relação entre as práticas discursivas exigidas fora da sala de aula e o que a escola ensina. Para tanto, é fundamental que os estudos morfológicos sejam levados à sala de aula para que o conhecimento a respeito da língua transponha os limites físicos da escola. 
Com base nos estudos de Perini (1996), Moura (2004) afirma que um bom caminho para amenizar - ou até quiçá solucionar - essa deficiência no estudo da Língua Portuguesa, seria trabalhá-la sob dois aspectos:

\begin{abstract}
formal, que diz respeito às questões de morfologia e de sintaxe (morfossintaxe) e semântico, o qual se refere ao sentido. Isso se faz necessário, pois a separação metodológica desses dois aspectos é que vai proporcionar o relacionamento, como já propunha Saussure (1973), entre forma e significado em um vocábulo, abordado, por ele, como signo: elemento dotado de significante (forma) e significado (conteúdo). (MOURA, 2004, p. 31).
\end{abstract}

Assim, a Morfologia deve ser estuda em parceria com a Sintaxe e a Semântica, bem como ser vista como um instrumento capaz de organizar e analisar os diversos conjuntos paradigmáticos do Português, por menores que sejam, com o intuito de evitar conflitos como o que será apresentado a seguir.

\title{
2. Vogal temática versus desinência de gênero: o conflito
}

A definição uniforme proposta nas gramáticas tradicionais é, certamente, uma das causas de confusão na hora de identificar se em determinada palavra há uma vogal temática ou uma desinência de gênero. Quanto ao desacordo entre os linguistas na definição de quando um determinado termo possui ou não vogal temática Cunha e Cintra (1985) dizem:

\footnotetext{
não há acordo entre os linguistas, quanto à inclusão das VOGAIS TEMÁTICAS entre os morfemas. Parece-nos que, assim como as desinências, elas fazem parte dos morfemas gramaticais categóricos, pois também distribuem os radicais em classes. Por si mesmas nada significam, mas poder-se-ia talvez dizer que, nos casos, a função é a significação. (CUNHA e CINTRA, 1985, p. 81).
}

A partir dessa ideia, e com base na análise das Gramáticas Normativas apresentadas neste estudo, pode-se dizer que o conceito internalizado nos falantes de que $-a$ e $-o$ são apenas marcas de feminino ou masculino, contribui para que o entendimento seja ainda mais complicado. Tanto que, Mauro José Rocha do Nascimento (2006, p. 87) demonstra que "a relação estreita entre vogais temáticas e gênero é de caráter cognitivo: os falantes, de modo geral, estabelecem uma relação imediata entre construções em $-o$ e o gênero masculino e construções em $-a$ e o gênero feminino".

A afirmativa de Nascimento (2006) é plausível, mas contestável como demonstra Leonardo Ricino (2015, p. 1), em seu artigo "Nossa língua não é machista", no qual fala que muitas palavras, hoje femininas, já foram masculinas e vice-versa, como é o caso de "o mapa usado como feminino até o século XVI; e a tribo, que, para os seiscentistas, era tão correto quanto o tribo". Além disso, Ricino afirma que vários termos da Língua Portuguesa terminam em $-a$, mas são masculinos em virtude do artigo definido que os acompanha, tais quais: "o guarda, o eczema, o formicida, o pirata, o agiota, o dia, o mapa (consideradas femininas até o século XVI)".

O senso comum de que as palavras terminadas em $-a$ são femininas e as terminadas em $o$, são masculinas poderá quiçá ser desmitificado, por uma "exceção", pois a que gênero pertencem as palavras terminadas em $-e$, se no português brasileiro não existe uma variante neutra como havia no Latim? Para esse questionamento, Ricino $(2015$, p. 2) ratifica que os termos com essa terminação são democráticos ao se dividirem entre os dois gêneros já estabelecidos, como: "o pente, o mestre, o dente, o telefone, o chicote, o cacete, o canivete, o guindaste, a grade, a mente, a hélice, a laringe, a faringe, a neve, a noite, a tese, a árvore".

Tendo sido esclarecida essa falsa associação entre o gênero das palavras e suas terminações, o próximo tópico surge para esclarecer, com base em grandes nomes dos estudos 
linguísticos, o que de fato vem a ser vogal temática nominal e desinência de gênero, e se há a possibilidade desses dois elementos mórficos coexistirem numa mesma palavra.

\section{Um mesmo conflito sob duas perspectivas diferentes: gramática normativa versus descritiva}

Com base na Gramática Normativa, que desde os primórdios de seu uso busca estabelecer os preceitos da norma culta, escrita e falada, e com o auxílio da Gramática Descritiva, que surgiu nesta pesquisa como pilar para a investigação de um fato da língua, nesta seção propõe-se um debate entre Evanildo Bechara, Celso Cunha, Lindley Cintra, Joaquim Mattoso Câmara Jr. e José Carlos de Azeredo, com o intuito de apresentar as diferentes visões que regem os estudos morfológicos desses autores no que se refere à discrepância que serve de tema para esta investigação: a diferenciação entre vogal temática nominal e desinência de gênero.

\subsection{Evanildo Bechara, Celso Cunha e Lindley Cintra}

Em sua gramática, Celso Cunha e Lindley Cintra (1985, p. 80) definem vogal temática como o indicador de conjugação de determinado verbo, localizando-se entre o radical e a desinência. Ressaltam, ainda, que as vogais temáticas somadas aos radicais formam os temas dos verbos. Assim sendo, segundo os autores, as vogais temáticas são características próprias das formas verbais.

A respeito das desinências nominais de gênero, Cunha e Cintra (ibidem) afirmam que elas servem para indicar se determinado substantivo, adjetivo ou alguns pronomes são masculinos ou femininos. Cintra (2004, p. 87) destaca, ainda, que "o gênero dos nomes seria definido morfologicamente para palavras em -o e $-a$, distribuindo-se as outras palavras por ambos os gêneros." Além disso, Alexsandra Ferreira da Silva (2005) ressalta que Cunha e Cintra (1985) consideram

\footnotetext{
tanto o "-o" de "menino" como o "-a" de "menina" como um morfema gramatical categórico - desinência de gênero (DG) -, que indica apenas uma flexão de gênero. Contudo, [...] fazem uma observação dizendo que a distinção feita entre sufixo e desinência pertence à análise mórfica tradicional e que se poderia simplificar a classificação desses morfemas gramaticais. (SILVA, 2005. p. 3-4).
}

Seguindo uma linha diferente, da exposta acima, Evanildo Bechara (2009), num mesmo trecho, em que fala dos elementos mórficos, dá a seguinte definição sobre vogais temáticas e desinências:

\footnotetext{
os elementos mórficos de significação interna, indicadores das flexões gramaticais, chamam-se desinências e dividem-se em nominais e verbais. [...] Muitas vezes o radical não pode funcionar imediatamente como palavra; completa-o com uma vogal para constituir o tema da palavra e por isso se chama vogal temática (BECHARA, 2009, p. 337).
}

Observa-se aqui que, diferente de Cunha \& Cintra (1985), Evanildo Bechara adere à proposição levantada por Joaquim Mattoso Câmara Jr. em 1970 e considera a existência das vogais temáticas nominais. No entanto, seguindo uma perspectiva distinta da adotada por Mattoso Câmara Jr., a respeito do tratamento da morfologia flexional de gênero, Bechara considera que o gênero masculino seja representado pelo morfema $-O$ e acrescenta que, nos nomes, as vogais, em certas palavras, possuem dupla função, pois, ao mesmo tempo em que são vogais temáticas também podem funcionar como desinências de gênero. "Exemplificando: em 
aluno, o -o seria vogal temática e desinência de gênero, dada a parelha aluno/aluna. Em livro, a vogal final é apenas temática" (DUARTE, 2006, p. 3) visto que a forma "livra" não é aceitável como seu feminino.

Vale ressaltar, no entanto, que na análise mattosiana, a palavra menino, por exemplo, apresenta a vogal temática -o e o gênero masculino zero. Portanto, para Joaquim Mattoso Câmara Jr., o morfema -o, desse vocábulo não é cumulativo, isto é, não acerca simultaneamente as funções de vogal temática e de marca flexional de gênero.

Ademais, a partir de Mattoso Câmara Jr. (1970), inicia-se uma linha de pensamento em que substantivos e adjetivos também teriam o elemento vogal temática, pois o estudioso considera ser de fundamental importância a utilização das vogais temáticas nos nomes, já que

$$
\begin{aligned}
& \text { pode-se justificar a existência desses morfemas tanto sincronicamente, } \\
& \text { depreendendo-os da forma dos vocábulos, quanto diacronicamente, por ser a vogal } \\
& \text { temática a vogal de desinência do acusativo das três primeiras declinações a que se } \\
& \text { conduziu o sistema flexional de casos do latim, e é do acusativo que se originam as } \\
& \text { formas do português. (MATTOSO CÂMARA JR., 1970, p. 200). }
\end{aligned}
$$

Entretanto, a teoria proposta por Mattoso Câmara Jr. divide opiniões, pois é parcialmente aceita por alguns autores, como José Carlos Azeredo (2000); negada completamente por tradicionalistas como Cunha e Cintra (1985) e aceita por Bechara, como ressalta Luiz Claudio Valente Walker de Medeiros (2005), no texto para o IX Congresso Nacional de Linguística e Filologia.

A esse respeito, Bechara (2009, p. 133) fala sobre a inconsistência do gênero gramatical e declara que a diferença de gênero é sem fundamento racional, pois considera apenas a tradição do uso e da norma. Essa afirmação traz à baila, novamente, a relação quase instintiva que é feita entre gênero gramatical e sexo, a respeito disso Mattoso Câmara Jr. faz uma importante observação sobre Franz Bopp:

Franz Bopp, o velho e verdadeiro criador da gramática indo-européia, admitiu que os homens primitivos indo-europeus tinham transferido a noção de sexo do reino animal para todas as coisas do universo, que assim lhes aparecia como um grande conjunto de machos e fêmeas (MATTOSO CÂMARA JR., 1972, p. 200).

Considerando que qualquer coisa aprendida inicia-se pelas vias cognitivas, é justificável e aceitável que exista tal confusão, por isso, Mauro José Rocha do Nascimento (2006) traz como evidência o fato dos falantes fazerem uma aproximação entre palavras terminadas em $-a$ como femininas e as terminadas em $-o$ como masculinas

\subsection{Mattoso Câmara Jr. e José Carlos Azeredo}

Segundo o Dicionário Priberam da Língua Portuguesa, a vogal temática constitui-se como elemento "que se junta ao radical de uma palavra para construir o tema". Evanildo Bechara, ao trabalhar as estruturas verbais em sua "Moderna Gramática do Português" (2009, p. 22), afirma que "o tema é a parte da palavra pronta para receber o sufixo ou a desinência", logo, no vocábulo "estudar", por exemplo, temos: radical: estud-, vogal temática: -a e desinência, neste caso de infinitivo: $-r$. No entanto, sabe-se que algumas formas verbais não seguem esse princípio, pois não possuem vogais temáticas, como é o caso dos verbos na $1^{a}$ pessoa do singular do subjuntivo, em que o elemento $-e$ de cant- $e$, por exemplo, marca o tempo e o modo, e não a vogal temática do verbo.

Como visto anteriormente, é a partir de Mattoso Câmara Jr. (1970) que os estudos linguísticos voltaram-se para a discussão a respeito do fato de que os nomes também seriam 
dotados, em sua estrutura, de vogais temáticas. Embora tal postulado tenha rapidamente se difundido entre diversos teóricos da língua, quando os olhares estão voltados para o estudo dos nomes, muita controvérsia surge, tanto que Said Ali, em sua Gramática Elementar da Língua Portuguesa, de 1965, ao tratar da classificação de substantivos (p. 21-36) e dos adjetivos (p. 38-41), não cita a vogal temática. Acompanhando o pensamento de Said Ali estão, ainda, Cunha e Cintra (1985) e Gladstone Chaves de Melo (1988).

A audaciosa proposição de Mattoso Câmara Jr., ao mesmo tempo em que foi rejeitada por muitos estudiosos da língua, também foi aceita e seguida por vários outros, mas, além do pressuposto de que alguns gramáticos negam a existência da vogal temática nominal, essa parte da Morfologia enfrenta ainda outro grande problema, isto é, a confusão desse elemento mórfico com a desinência de gênero. De acordo com José Azeredo (2000, p. 70-72) "[...] existem vogais temáticas nominais, que enquadram as palavras em três classes temáticas: tema em -o (poço, profundo, outro), tema em - a (atleta, bala, secura) e tema em -e (ponte, alegre, corrente, aquele, presidente)", no entanto, o autor ratifica que existem, assim como nos verbos, nomes atemáticos, isto é, aqueles que não trazem a vogal temática em sua estrutura, como é o caso das palavras terminadas em vogal tônica (cafệ, tatu, jiló, garçom, metrô) e em consoante (lençol, colher, freguêss).

Ao validar essa premissa, Azeredo vai de encontro ao pensamento de teóricos que negam a existência desse elemento mórfico, pois, a partir de suas palavras, é possível afirmar que a "atematicidade" constitui-se como uma exceção à "regra" da "tematicidade", que é inerente tanto aos verbos quanto aos nomes.

Ainda sobre a querela morfológica acerca da estrutura das palavras, eis que surge a necessidade da conceituação de desinência de gênero. Para tanto, faz-se necessário retomar aquela linha de raciocínio do senso comum, inerente aos falantes da Língua Portuguesa, na qual as palavras terminadas em $-o$ são masculinas e aquelas que terminam em $-a$ são femininas. A esse respeito, Mattoso Câmara Jr. (1972, p. 100) expõe que apenas a forma - a poderia ser validada como desinência de gênero, visto que, "a forma masculina seria considerada uma forma não marcada morfologicamente".

A observação mattosiana é extremamente plausível, visto que tal afirmação acaba por abarcar um conjunto de palavras masculinas, "antes relegadas às listas de exceções, tais como português, professor, peru, parente" (ibidem); e define que apenas a presença da desinência - $a$ marcaria o feminino, pois, logo, sua ausência indicaria o gênero masculino.

A partir dessas afirmações, pode-se inferir que a vogal temática prepara o nome para receber uma desinência, e que ela, ou sua ausência, é responsável por marcar a oposição entre masculino e feminino. Logo, é facilmente aceitável dizer que no substantivo "namoradas", por exemplo, o $-a$ pode ser classificado como desinência de gênero feminino. Já em "namorados", a ausência do morfema anteriormente mencionado faz com que este vocábulo seja masculino. Além disso, a partir da análise desses dois vocábulos e de outros pares, como meninas-meninos e amigas-amigos, pode-se extrair outra conclusão: a de que desinência de gênero e vogal temática podem coexistir numa mesma palavra.

Com base nos estudos de Mattoso Câmara Jr., a respeito da flexão nominal de gênero, para analisar os exemplos citados, é possível afirmar que, o masculino, como forma nãomarcada, tem por característica a desinência zero (Ø). Já o feminino, isto é, a forma marcada, surge por meio do acréscimo do morfema $-a$. Assim sendo, a formação do gênero feminino está embasada nas regras de alterações morfofonológicas, como elisão, alternância vocálica e outras.

Ademais, $-a$ também exerce, às vezes, a função de vogal temática, visto que esse morfema faz o elo entre o radical e a flexão de número plural em casos, como namorad- e amig-, que 
formam os temas namorada(o) - e amiga(o) - respectivamente, já que construções como namorad(s) e amig(s), por exemplo, não seriam possíveis na Língua Portuguesa.

Trabalhando com a dualidade acima poder-se-ia, quiçá, apaziguar uma parcela das controvérsias morfológicas difundidas pelas gramáticas normativas e descritivas. Diga-se apenas uma parcela, porque essa singela hipótese não é capaz de contemplar o grande grupo de palavras que compõem a lexicografia da Língua Portuguesa como é o caso de pares, como barco-barca, cintocinta e jarro-jarra, em que $-a$ e $-o$ indicam uma mudança semântica e não fazem referência ao conceito de masculino ou feminino desses vocábulos.

Portanto, pode-se concluir que em se tratando de seres não animados, como os citados, não há uma distinção quanto ao gênero, mas sim referente a uma especialização ou subtipo da palavra "primitiva". Assim sendo, barca seria outro tipo de barco; cinta seria um subtipo de cinto e jarra seria uma especificação de jarro.

\section{CONSIDERAÇÕES FINAIS}

O presente trabalho buscou, com base no diálogo entre grandes estudiosos da linguagem, conceituar vogal temática nominal e desinência de gênero, bem como compreender e esclarecer a confusa associação entre gênero e as terminações das palavras, feita pelos falantes da Língua Portuguesa. Para que esse esclarecimento fosse possível, conclui-se que a hipótese de que esses elementos mórficos possam coexistir numa mesma palavra é totalmente plausível.

Sobre as diversas perspectivas apresentadas nesta investigação, vale retomar a ideia de que as gramáticas tradicionais propõem que nos seres animados há desinência de gênero em nomes terminados em $-a$ e $-o$ e vogais temáticas em seres não-animados finalizados com as mesmas terminações. No entanto, a perspectiva mattosiano apresentada surge para ratificar que existe certa sistematização dos gêneros na Língua Portuguesa, pois a flexão é responsável pela mudança semântica de certas palavras; como nos pares jarro/jarra em que o linguista discute a respeito da oposição entre gêneros masculino e feminino e especifica que o masculino caracteriza a forma não marcada e o feminino uma especialização.

Além dessas considerações, é importante salientar, também, o pensamento de Azeredo a respeito da existência das vogais temáticas nominais, que acabam por subdividir o léxico em três classes temáticas; bem como sua perspectiva sobre a "atemacidade" nominal que se constitui como uma exceção à "regra" da "tematicidade", inerente tanto aos verbos quanto aos nomes.

Portanto, pretendemos com o presente trabalho, trazer contribuições para o campo de pesquisas dos Estudos da Morfologia, para fomentar a reflexão sobre as perspectivas de ensinoaprendizado e para estimular outras investigações científicas acerca dos postulados das Gramáticas Normativa e Descritiva.

\section{REFERÊNCIAS BIBLIOGRÁFICAS}

ANDRADE, Amália; VIANA, Maria do Céu. In: MATEUS, Maria Helena Mira et al. Fonética, fonologia e morfologia do português. Lisboa: Universidade Aberta, 1990.

ARAÚJO, Edna Lira do Nascimento. Flexão de sexo, derivação de gênero: encontros e desencontros na descrição e no ensino de gênero dos substantivos. 2003. 157 f. Dissertação (Mestrado em Letras). Rio de Janeiro, Universidade do Estado do Rio de Janeiro. Disponível em: < http://www.pgletras.uerj.br/bancoteses_mlp.php\#topo>. Acesso em: 11 out. 2015. 
AZEREDO, José Carlos de. Fundamentos de gramática do português. Rio de Janeiro: Jorge Zahar, 2000.

BAGNO, Marcos. Gramática pedagógica do português brasileiro. São Paulo: Parábola Editora, 2011.

BASÍLIO, Margarida. Estruturas lexicais do português. Petrópolis, Vozes, 1980.

Segmentação e classificação de morfes. In: Estudos de lingüística e língua portuguesa I. Rio de Janeiro. Cadernos da PUC-RJ, 1974.

BECHARA, Evanildo. Moderna gramática portuguesa. 37. ed. rev. e ampl. E atual. conforme o novo Acordo Ortográfico Rio de Janeiro: Nova Fronteira, 2009.

BENITES, Sônia Aparecida Lopes. A análise lingüistica na sala de aula. Anais do XIV Seminário do Cellip - Curitiba, 2001 - pp. 1820-1825.

CARVALHO, José Gonçalo Herculano de. Teoria da linguagem vol. 2. Coimbra, Atlântida Editora, 1974.

CASAGRANDE, Fernanda Couto Guimarães. Lingua falada e língua escrita. Disponível em: <http://bit.ly/2avY91i>. Acesso em: 04 ago. 2016.

CAVALIERE, R. Fonologia e Morfologia na Gramática Científica Brasileira. Niterói: EdUFF, 2000.

CRYSTAL, David. A revolução da linguagem. Rio de Janeiro: Zahar, 2005.

CEREJA, William Roberto; MAGALHÃES, Thereza Cochar. Português: linguagens. 5. ed. São Paulo: Atual, 2005.

CINTRA, Geraldo. A Flexão Nominal em Mattoso Câmara e Outras Análises. In: DELTA. [online]. 2004, vol. 20, $\mathrm{n}^{\circ}$ especial p. 85-104. Disponível em:<www.scielo.br/scielo.php?script=sci_arttext\&pid=S0102-

44502004000300008\&lng=en\&nrm=iso >. ISSN 0102-4450. Acesso em: 11 out. 2015.

CUNHA, Celso \& CINTRA, Lindley. Nova gramática do português contemporâneo. $2^{\mathrm{a}}$ ed. Rio de Janeiro: Nova Fronteira, 1985.

DICIONÁRIO PRIBERAM DA LÍNGUA PORTUGUESA. Disponível em: <http://www.priberam.pt/dlpo/>. Acesso em: 09 out. 2015.

DUARTE, Paula Mosânio Teixeira. Do estatuto mórfico da vogal temática e do morfema de gênero em português. Disponível em: < http://www.filologia.org.br/revista/artigo/7(23)06.htm>. Acesso em: 16 mar. 2017.

FARACO, Carlos Emilio; MOURA, Francisco Marto; MARUXO JÚNIOR, José Hamilton. Língua Portuguesa: Linguagem e interação. São Paulo: Ática, 2010.

FREIRE, Paulo. A importância do ato de ler: em três artigos que se completam. São Paulo: Cortez, 1987.

FREITAS, Ernani Cesar de. Linguagem e Comunicação Social. Revista Virtual de Estudos da Linguagem, 2006, v. 4, n. 6, p. 1-4. 
FREITAS, Horácio Rolim de. Princípios de Morfologia. 4a ed. Rio de Janeiro: Oficina do Autor, 1997.

LAROCA, Maria Nazaré de Carvalho. Manual de morfologia do português. Campinas: Pontes/EDUFJF, 1994.

LIMA, Carlos Henrique da Rocha. Gramática normativa da língua portuguesa. Rio de Janeiro: José Olympio, 1976.

MACAMBIRA, José Rebouças. A estrutura morfo-sintática do português: aplicação do estruturalismo lingüistico. 5. ed. São Paulo: Pioneira, 1987.

MACEDO, Walmírio. Gramática da Lingua Portuguesa. Rio de Janeiro: Presença, 1991.

- Elementos para uma estrutura da Lingua Portuguesa. 2a ed. Rio de Janeiro: Presença, 1987.

MARCUSCHI, Luiz Antônio. Da fala para a escrita: atividades de retextualização. 2. ed. São Paulo: Cortez, 2001.

MARCUSCHI, Luiz Antônio; DIONISIO, Angela Paiva. (Orgs.). Fala e escrita. Belo Horizonte: Autêntica, 2007.

MATTOSO CÂMARA Jr., Joaquim. Dicionário de filologia e gramática. São Paulo: Iozon, 1968. . Estrutura da língua portuguesa. 19. ed. Petrópolis: Vozes, 1970.

. Princípios de lingüistica geral. 4. ed. Rio de Janeiro: Livraria Acadêmica, 1972.

. Dispersos. Rio de Janeiro: Fundação Getúlio Vargas, 1973.

Dicionário de lingüistica e gramática. 13. ed. Petrópolis: Vozes, 1986

História e estrutura da língua portuguesa. 3. ed. Rio de Janeiro: Padrão, 1979.

MEDEIROS, Luiz Claudio Valente Walker de. Vogal Temática Nominal. In: Congresso Nacional de Linguística e Filologia Em homenagem a Said Ali. No 11. 2005. Rio de Janeiro. Anais... 2005. Disponível em: <http://www.filologia.org.br/ixcnlf/15/23.htm> Acesso em: 11 out. 2015.

MELO, Gladstone Chaves de. Iniciação à Filologia Portuguesa. 6. ed. Porto Alegre: Organização Simões, 1988.

MONTEIRO, José Lemos. Morfologia portuguesa. Fortaleza: EDUFC, 1986.

MOURA, Renata Boregas Santini de. Abordagem gramatical nos livros didáticos: análises e sugestões. Disponível em: < http://bit.ly/2m9txtC>. Acesso em: 04 mar. 2017.

NASCIMENTO, Mauro José Rocha do. Repensando as vogais temáticas nominais a partir da gramática das construções. 2006. 171 f. Tese (Doutorado em Letras Vernáculas - Língua Portuguesa). Faculdade de Letras, Universidade Federal do Rio de Janeiro. Disponível em: 
<http://www.letras.ufrj.br/posverna/doutorado/NascimentoMJR.pdf> Acesso em: 11 out. 2015.

O gênero do português e suas relações morfo-semânticas. Revista Eletrônica do Instituto de Humanidades, ISSN-1678-3182, Volume II, Número VI - Jul-Set 2003. Disponível em: $\quad<$ http://publicacoes.unigranrio.com.br/index.php/reihm/article/viewFile/423/415>. Acesso em: 18 out. 2015.

PERINI, Mário. Niveis de detalhamento na descrição gramatical: uma perspectiva pedagógica. Trabalhos em Lingǘstica Aplicada no 12. Campinas: Unicamp/IEL - setor de publicações, 1988.

PETIT, Michèle. Os jovens e a leitura: uma nova perspectiva. São Paulo: Editora 34, 2008.

POSSENTI, Sírio. Por que (não) ensinar gramática na escola. Campinas, São Paulo: Mercado das Letras, 1996. 95p.

ROCHA LIMA, Carlos Henrique da. Estruturas Morfologicas do Português. Belo Horizonte: UFMG, 1998.

ROSA, Maria Carlota. Introdução à morfologia. São Paulo: Contexto, 2000.

RICINO, Leonardo. Nossa língua não é machista. Disponível em: $<$ http://conhecimentopratico.uol.com.br/linguaportuguesa/gramaticaortografia/23/artigo178963-1.asp>. Acesso em: 17 out. 2016.

SANDMANN, Antônio José. Morfologia geral. São Paulo: Contexto, 1991.

SILVA, Alexsandra Ferreira. Considerações sobre o morfema de gênero "-a". Disponível em: $<$ http://www.filologia.org.br/cluerj-

sg/anais/ii/completos/comunicacoes/alexsandraferreiradasilva.pdf>. Acesso em: 17 fev. 2017.

SILVEIRA, Olmar Guterres da. Fundamentos da Análise Morfológica in A Obra de Olmar Guterres da Silveira - sua contribuição aos estudos das línguas portuguesa e latina. Organizada por Horácio Rolim. Rio de Janeiro: Metáfora, 1996.

UCHÔA, Carlos Eduardo Falcão (Org.). Dispersos de J. Mattoso Câmara Jr. Rio de Janeiro: Lucerna, 2004.

ZANOTTO, Normelio. 1986. Estrutura Mórfica da Lingua Portuguesa. Caxias do Sul: EDUCS. 